\title{
Пути Использования Медико-Статистических Данных Населения Азербайджана в Единой Информационной Системе
}

\author{
Гюлара Мурадова ${ }^{1}$, Жаля Джамалова ${ }^{2}$ \\ ${ }^{1}$ Азербайджанский Технический Университет \\ ${ }^{2}$ Азербайджанский Государственный Университет Нефти и Промышленности \\ 'gularamu@aztu.edu.az, ${ }^{2}$ camalova565@mail.ru
}

\begin{abstract}
Аннотация- Для обеспечения современных методов управления системой здравоохранения Азербайджана в статье определены этапы организации и анализа медицинских статистических данных. Показаны механизмы и инструменты совершенствования управления системой здравоохранения за рубежом. Рассмотрена целесообразность использования технологий Big Data для обработки медикостатистических данных в режиме реального времени.
\end{abstract}

Ключевые слова- медико-статистические данные, электронная медицинская карта, электронная медицина, здравоохранение, big data, электронный обмен данными, база данных медицинских услуг

\section{I. ВВЕДЕНИЕ}

Основная задача электронной медицины заключается в обеспечении простого и удобного доступа к необходимой информации для оказания помощи населению в части взаимодействия медицинских организаций, создания оперативного инструмента анализа управления системой здравоохранения. Эффективность управления означает предоставление единых средств коллективной работы с информацией для анализа данных, формирования стандартной отчетности, ведения оперативного мониторинга различных показателей деятельности. От соблюдения единых правил сбора, обработки медикостатистических данных, их кодирования зависит достоверность получаемых данных, что позволяет принимать адекватные управленческие решения по улучшению организации здравоохранения, а также реализовывать профилактические программы, направленные на снижение заболеваемости и смертности населения. Контроль за процессом лечения, определение наиболее эффективных методов лечения позволяют решить технологии Big Data.

\section{II. СИСТЕМЫ ЕДИНОГО ИНФОРМАЦИОННОГО ПРОСТРАНСТВА В СФЕРАХ ЗДРАВООХРАНЕНИЯ ЗАРУБЕЖОМ}

Проекты в сфере информатизации здравоохранения имеют особую специфику, так как ведение истории болезни, лабораторные системы, системы диагностики, построенные на базе компьютеров, характерны только для медицинской отрасли. Отказ от ведения бумажной документации в медицинской сфере упрощает сбор, накопление и анализ данных, характеризующих состояние здоровья людей, а также формирование отчетности для принятия правильных управленческих решений в сфере здравоохранения. Используя возможности программных продуктов, врач может прямо на рабочем месте внести все необходимые данные о результатах осмотра пациента. На основе ведения первичной медицинской документации и медицинских архивов в электронном виде проводятся необходимые вычисления автоматизированной обработки персональных данных пациентов. Для идентификации и ведения электронной медицинской карты (ЭМК) населения создаются программно-аппаратные комплексы для реестра государственных информационных ресурсов. Медицинская информационная система (МИС) собирает и агрегирует все данные о пациенте, обеспечивает совместное использование медицинскими подразделениями и их анализ в реальном времени для обоснования выполнения необходимых действий $[1,2]$. Затем с помощью систем поддержки принятия решений определяется:

- необходимость обработки структурированной, слабо структурированной и не структурированной информации больших объемов;

- расширение состава сведений за счет данных, получаемых от анализа демографических показателей службы государственной статистики;

- реализация функций геоинформационного представления сведений;

- обеспечение возможности автоматического формирования текстовых документов (автосправок);

- применение методов статистической обработки и прогнозирования [3].

Формирование полноценной информационной системы здравоохранения невозможно без создания единого информационного медицинского пространства, включающего все медицинские учреждения административной территории и объединяющего любую информацию независимо от последующего ее использования различными службами в медикосоциальных и экономических целях. Это позволяет получать необходимые статистические данные на основе 
обработки соответствующей первичной информации. В информационных системах оперативный доступ обеспечивается за счет прямых запросов при условии, что информация в базе данных собирается автоматически, в требуемом объеме и номенклатуре данных. В таких системах сочетается графическое представление структуры или данных с количественными показателями в виде абсолютных цифр или процентных отношений. При этом достигается любая степень детализации в рамках информационных полей, определенных для собираемой информации. Медицинские учреждения могут обращаться за конкретным информационным сервисом, генерирующим необходимые интерфейсы учреждениям, независимо от местоположения. Для организации электронного обмена медицинскими данными и обеспечения производительной управляемой связи, между центрами обработки данных и региональными центрами, необходима организация стабильных и производительных каналов связи для всех медучреждений. Объемы хранимой информации растут настолько быстро, что превосходят пропускную способность существующих медицинских информационных систем. Для передачи данных по всем регионам применимы облачные технологии и Big Data. Обработка данных, исходя из принципов облачных сервисов, организовывается как распределенная система виртуальных ресурсов. В зависимости от загрузки, конкретная информация или приложение могут быть предоставлены разными устройствами. Важно стандартизовать процессы медицинских услуг, создавая единые реестры, справочники и классификаторы. Обработка статистической информации в режиме реального времени с применением технологий больших данных сокращает нагрузки на практическое звено, повышает достоверность собираемых данных и формируемых отчетов. Анализ и обработка больших данных, относящихся к определенным регионам и группам населения, улучшают планирование медицинского обслуживания [4, 5]. В настоящее время многие страны реализуют программы по созданию единого информационного пространства в сферах здравоохранения. Концепция информатизации здравоохранения заключается в том, что в центре находится пациент, забота о здоровье пациента и вокруг него врачи, лаборатории, клиники, дистанционное обслуживание. Анализ динамики применений технологий Big Data зарубежом показал, что с наибльшей активностью ведутся разработки ,призванные решить проблемы комплексного анализа данных, поступающих из многочисленных источников в режиме реального времени для решения диагностических задач.

В Нидерландах на базе института информатизации здравоохранения NICTIZ, проекта AORTA, создан государственный центр сбора и обработки персонифицированных медицинских данных граждан страны. Диспетчерский центр $L S P$ - сервер управляет доступом к медицинским данным. Граждане Голландии, находясь за пределами своей страны, могут получать квалифицированную медицинскую помощь [6].
Внедрены современные методы управления системой здравоохранения в Канаде: электронный паспорт здоровья, инфраструктура, телемедицина, создание национальных реестров, справочников и классификаторов, системы диагностической визуализации и хранения графической информации .

IBM Advanced Care Insights объединяет в себе три аналитических технологии, предоставляющие медицинским учреждениям статистическую информацию, полученную из клинических, социальных и анкетных данных. Для преобразования данных в полезную информацию в комплекте решений используется обработка данных на естественном языке, позволяющая извлекать ценные данные из записей врачей, результатов анализов в ЭМК. Используя такую подробную информацию о пациентах, медицинские учреждения могут применять прогнозный анализ, чтобы выявлять факторы риска, классифицировать пациентов по рискам, определять передовые практики и набор критериев для направления пациентов к врачам [7].

Аналогичная комплексная программа реализуется в США. МИС Vista (Veterans Health Information Systems and Technology Architecture) в США является разветвлённой системой охватывающей практически все аспекты медицинского обслуживания обеспечивает медицинское обслуживание 4 миллионов ветеранов. В системе работает 180 тыс. сотрудников в 163 госпиталях, 800 клиниках и 135 домах ухода. Система имеет порядка ста прикладных пакетов программ, начиная с учёта управления оборудованием и до экспертных систем принятия медицинских решений [8].

Приоритетные направления от Microsoft Empowering Health предоставляют большие возможности для пользователей и обеспечивают:

- организацию электронных коммуникаций;

- предоставление единых средств коллективной работы с информацией для анализа данных, формирование стандартной отчетности, ведение оперативного мониторинга различных показателей деятельности;

- способность накапливать, хранить и предоставлять для анализа любой объем разнородных по типу данных;

- информационное взаимодействие между компонентами информационных систем;

- комплексное обеспечение информационной безопасности; [9].

- управление ресурсами информационной системы

Облачные платформы хранения ЭМК с большим количеством сопутствующих услуг, порталы пациентов, анализ данных, аналитика здравоохранения реализованы на американской платформе PracticeFusion. Бесплатная информационно-аналитическая система PracticeFusion позволяет перенести все организационные процессы в онлайн, а пациенты и врачи могут получать доступ к 
информации с телефонов и планшетов. Виртуальные клиники ознакамливают пациетов с медицинскими рекомендациями врачей, а также с результатами обледований, есть возможность получить ответы на возникающие конкретные вопросы. Предусмотрена как текстовая, так и фото и видеоинформация [10].

Современные технологии организации и оказания диагностических, лечебных, реабилитационных и профилактических услуг применяемые в зарубежных странах, необходимо внедрять в системы управления качеством медицинской помощи в Азербайджане.

\section{III. ПУТИ ПРИМЕНЕНИЯ МЕДИКО- СТАТИСТИЧЕСКИХ ПОКАЗАТЕЛЕЙ ЗДОРОВЬЯ НАСЕЛЕНИЯ АЗЕРБАЙДЖАНА В ЕДИНОЙ ИНФОРМАЦИОННОЙ СИСТЕМЕ}

Информационная поддержка в сфере здравоохранения может помочь в интеграции накопленных статистических данных. Азербайджан стремится к обеспечению наиболее благоприятного развития демографических процессов и улучшение здоровья населения. Согласно статистических данных 2016 года население Азербайджана составляет 9, 613 млн. человек. Из них 53,1 \% городские жители, 46,9 \% сельские жители. 49,8 \% населения являются мужчинами, a 50,2 \%- женщины. На период 2015-2016 г. на каждые 1000 мужчин в среднем приходилось 1007 женщин [11]. В связи с тем, что в последние годы рождаемость мальчиков выше, чем девочек, ситуация будет меняться. Так в 2015 г. зарегистрировано 53.2\% рожденых мальчиков и $46.8 \%$ девочек. Средняя продолжительность жизни у мужчин71.6 лет, а женщин - 76.8 лет. Рождаемость детей составляет 18.5 на 1000 человек. В среднем на каждую женщину на протяжении всей её жизни приходится два родившихся ребенка. Министерству здравоохранения в 2006 г. приказом №143 Правительством Азербайджана был поручен перевод в электронный вид статистических данных о здоровье населения т.е. формирование Электронной карты здоровья. На Интернет портале e-helth хранятся электронные персональные медицинские записи относящихся к человеку. Эта информация заносится в электронный регистр, начиная с рождения ребенка. Также существуют реестры больных гемофилией, талассемией, диабетом. Планируется электронная база данных медицинских услуг по всем направлениям. Одновременно нужно решать вопрос интеграции в единую базу данных информации о наблюдаемых при неотложных состояниях проявлениях заболевания, эффективности применявшихся медикаментов. Это важно для последующего лечения этих больных врачами районных поликлиник. Создаются новые условия для оперативного получения необходимой информации врачами скорой медицинской помощи непосредственно при оказании экстренной помощи. В стране функционируют 77 отделений (станций) скорой помощи. Машины медицинской помощи оснащены электронным оборудованием для доступа к электронным картам. Врачу скорой помощи очень важна информация о хронических болезнях или аллергии на лекарства. Быстрый доступ к таким данным посредством ЭМК поможет оказать квалифицированную помощь. Проблемами остаются оперативное получение достоверных первичных данных об объемах и качестве медицинской помощи, оказываемой медицинскими организациями, профилактика и раннее диагностирование заболеваний. В Азербайджане на 2014 год зарегистрировано 9543 человека с злокачественными новообразованиями. Из них 81 ребенок в возрасте до 13 лет и 28 детей возрасте от 14-17 лет. Организация единого подхода к сбору и обработке медико-статистической информации поможет выявлению этих заболеваний на ранней стадии.

По статистическим показателям 2014 года в стране среди населения старше 18 лет 8,1\% инвалидов I группы, $71,9 \%$ - II группы и 20\% -III группы. 11199 - детей инвалидов в возрасте от 0 до 18 лет. Этим категориям населения с ограниченными возможностями необходим индивидуальный подход в режиме online, что даст возможность консультироваться с врачом относительно действия лекарств, диагнозов, планов по уходу, а также отслеживать фактические данные влияния лекарств. По статистическим данным на период 2014 - 2015 гг. в Азербайджане, зарегистрировано 25152 инсулинозависимых больных диабетом. Эти людям небходимо использовать различные устройства с подключением к сети, чтобы периодически, отправлять такие данные, как уровень сахара в крови, для медицинской документации, необходимой врачам и диабетологам [5]. Социологический опрос среди женщин в возрасте 15-49 лет показал, что в стране нужны системы удаленного мониторинга, позволяющие решать проблемы доступности медицинской помощи. Согласно статистики не обращаются за медицинской помощью в государственные лечебные учреждения по причине медико-технологического и организационного характера: отдаленность медицинского учреждения от места проживания - 36,6\%, отсутствие транспорта - 35,6\%, если требовалось сопровождения $44,8 \%$, отсутствие специалистов - 52,1\% [12]. В Азербайджане на 2016 год зарегистрировано 567 учреждений здравоохранения. Для анализа разнородных по типу данных недостаточно наличия разрозненных систем. Несмотря на увеличение числа е-услуг в сфере здравоохранения нужна интеграция существующих программных решений, предоставление обмена медицинской информацией между больницами, клиниками, т.е. необходимо связывать воедино системы всех медицинских подразделений.

Для оценки состояния здоровья населения, в том числе медико-демографической ситуации системы здравоохранения в условиях медико-территориального районирования, прежде всего необходимо определить базу данных медицинских услуг, в которую входят [13]:

- пациенты с электронными медицинскими картами;

- медицинские учреждения здравоохранения, осуществляющие автоматизированную запись на прием к врачу с использованием сети Интернет и информационносправочных сенсорных терминалов;

- медицинские учреждения здравоохранения, использующие электронный документооборот при обмене медицинской информацией. 
Нужны механизмы и инструменты совершенствования системы управления в области охраны здоровья населения, предполагающие: создание единой электронной регистратуры, усовершенствование электронной медицинской карты, организацию информационного взаимодействия между амбулаторнополиклиническим звеном, планирование численности медицинского персонала с учетом демографической ситуации в регионе, современные средства контроля и мониторинга медико-демографических показателей рождаемости, заболеваемости, инвалидности, смертности, а также отслеживание изменения данных медицинского учета, облачные вычисления для сферы здравоохранения. В связи с мероприятиями по оптимизации программного обеспечения для сбора, приема и обработки медицинской статистической отчетности определены следующие этапы[3]:

- интеграция в единую информационную систему в здравоохранении систем сбора и обработки статистической отчетности;

- формирование заполненных бланков форм в защищенном от редактирования формате;

- переход на формат удаленного внесения данных и работы по «облачным» технологиям;

- возможность web-удаленного взаимодействия со специалистами службы медицинской статистики в районах Азербайджана посредством телекоммуникационного программного обеспечения.

Для получения оперативной информации необходимо иметь возможность работы со статистическими данными персональных данных пациентов, а также с данными, поступающие от различных лабораторий, стационаров. Специальное алгоритмическое обеспечение для работы с Big Data позволяет выполнять поиск скрытых закономерностей в таких данных. Данные, аккумулируются на едином портале, реализуют схему взаимодействия. Анализ медико-статистической информации о состоянии здоровья населения и деятельности различных типов медицинских организаций Азербайджана позволяет модернизировать систему здравоохранения, максимально адаптировав к современным реалиям и требованиям времени. Решение ключевых задач в рамках внедрения современных МИС в Азербайджане является целью повышения качества и доступности медицинских услуг.

\section{ЗАКЛЮЧЕНИЕ}

Для эффективного управления и функционирования в едином информационном пространстве, информационные ресурсы и технологии обработки информации в здравоохранении предполагают требуемый уровень централизации и координации работ:

- формирование оперативной отчетности на основе статистической информации, поступающие в режиме реального времени;

- обеспечение населения медицинской помощью в амбулаторно-поликлиническом звене в режиме онлайн;
- принятие мер по повышению доступности и качества медицинской помощи на удаленных территориях;

- применение современных медицинских стандартов информационного обмена;

- готовность к интеграции в государственную систему медицинского учета.

Применение технологий Big Data для анализа медикостатистической информации о состоянии здоровья по группам населения, территориальным и другим признакам, в информационно-аналитических системах, способствует улучшению медико-демографической ситуации, обеспечивая увеличение продолжительности жизни. Решение задач информационного взаимодействия различных организаций здравоохранения, которые рассмотрены в статье, будут способствовать применению современных медицинских стандартов информационного анализа статистических данных о состоянии здоровья населения Азербайджана и тем самым обеспечит совершенствование электронной системы медицины в Азербайджане.

\section{ЛИТЕРАТУРА}

[1] Н.Е. Кречетов, В.А. Кондратенков, Ю.В. Зеленская, «Международный опыт использования технологий intersystems в здравоохранении», Врач и информационные технологии, 2006, №4, c. $25-30$.

[2] J. Kern, K. Fister, O. Polazek, "Active patient role in recording health data Health Information Systems”, 2009, vol.1, pp. 1545-1547.

[3] В.И. Стародубов, А.В. Поликарпов, «Система поддержки принятия решений», Врач и информационные технологии, 2016, №1, с. 41-43.

[4] Г.И. Мурадова, «Большие данные в системе здравоохранения», İnformasiya texnologiyaları problemləri, 2016, №2, c. 25-30.

[5] Г.И. Мурадова, «Применение технологий big data для упрощения систем электронного документооборота», Elmi әsərlər, АзТУ 2014, №3, c. 35-39.

[6] П.П. Кузнецов, А.П. Столбов, «Информационные технологии в здравоохранении Европейского союза», Врач и информационные технологии, 2007, № 6, стр.70-71.

[7] Advanced Care Insights:,

[8] http://www-03.ibm.com/software/products/ru/advanced-care-insights

[9] https://ru.wikipedia.org/wiki/VistA

[10] https://partner8.microsoft.com/ru-ru/solutions/health

[11] http://www.practicefusion.com/

[12] The State Statistical Committee of the Republic of Azerbaijan:, http://stat.gov.az/

[13] Demographic and Health Survey 2006:, http://dhsprogram.com/pubs/pdf/FR195/FR195.pdf

[14] Е. Аверченко, «Управление здоровьем и здравоохранением: целеполагание и инструментарии решения на уровне субъекта федерации», КГМУ, 2013, с. 10-32. 